\title{
Efficacy and safety of icotinib in patients with brain metastases from lung adenocarcinoma
}

This article was published in the following Dove Press journal:

OncoTargets and Therapy

17 May 2016

Number of times this article has been viewed

Jianping $\mathrm{Xu}$

Xiaoyan Liu

Sheng Yang

Xiangru Zhang

Yuankai Shi

Department of Internal Medicine, Cancer Hospital, Chinese Academy of Medical Sciences, Beijing, People's Republic of China
Correspondence: Yuankai Shi Department of Medical Oncology, Beijing Key Laboratory of Clinical Study on Anticancer Molecular Targeted Drugs, National Cancer Center/Cancer Hospital, Chinese Academy of Medical Sciences and Peking Union Medical College, No 17 Panjiayuannanli, Chaoyang District, Beijing 10002I, People's Republic of China

Tel +861087788293

Fax +86 I0 87778740

Email syuankai@cicams.ac.cn
Objective: The objective of this study was to evaluate the efficacy and safety of icotinib in patients with brain metastases (BMs) from lung adenocarcinoma.

Patients and methods: Clinical data of 28 cases with BMs from lung adenocarcinoma were retrospectively analyzed. All the patients took $125 \mathrm{mg}$ icotinib orally three times a day. Progression of disease, intolerable adverse reactions, and number of deaths were recorded.

Results: For all the patients, the remission rate of icotinib was $67.8 \%$ and the disease control rate was $96.4 \%$. The median overall survival time of patients was 21.2 months, and the median progression-free survival time of patients was 10.9 months. Only mild adverse events of grade $1 / 2$ were observed during the treatment.

Conclusion: Icotinib was an effective and safe strategy to treat patients with BMs from lung adenocarcinoma.

Keywords: icotinib, lung adenocarcinoma, brain metastases

\section{Introduction}

Non-small-cell lung cancer (NSCLC) accounts for $80 \%-85 \%$ of all lung cancer cases, and is the leading cause of cancer-related death worldwide ${ }^{1}$ and the majority of patients present with advanced disease. ${ }^{2}$ NSCLC is characterized by a high incidence of central nervous system metastases, with $30 \%-50 \%$ of NSCLC patients developing brain metastases (BMs), ${ }^{3}$ and lung cancer is one of the most common causes of BM, especially adenocarcinoma. ${ }^{4}$ Patients with BMs experience significant morbidity and a reduced quality of life, often with neurological dysfunction and cognitive impairment, as well as a poor prognosis, with a median survival time of 3-6 months; less for patients without treatment for 4-11 weeks. ${ }^{5-7}$

Owing to the ineffectiveness of the majority of chemotherapeutic drugs to penetrate the blood-brain barrier (BBB), it is difficult for common chemotherapy drugs to improve the survival of patients with BMs.$^{8-10}$ The introduction of epidermal growth factor receptor tyrosine kinase inhibitors (EGFR-TKIs) brought new hope to advanced NSCLC patients. EGFR-TKIs, such as gefitinib and erlotinib, with their small molecular weight and ability to penetrate BBB to some extent, provided a certain efficacy in patients with BMs with relatively less adverse reactions compared with traditional chemotherapy. In clinical studies, the remission rate (RR) of gefitinib for NSCLC patients with BMs was reported to be from $10 \%$ to $38 \%$ and the median response time was 9-13.5 months. ${ }^{11-13}$ Erlotinib also showed effectiveness for patients with BMs. ${ }^{14-16}$ Studies indicated that activating mutations of the EGFR gene are strongly predictive of response to EGFR-TKIs in NSCLC. ${ }^{17,18}$ EGFR-TKIs are recommended for all lines of treating advanced NSCLC with activating mutations 
of EGFR, but the role of EGFR-TKIs in EGFR wild-type NSCLC is still debatable. ${ }^{19}$

Icotinib, an orally administered EGFR-TKI, showed potent antitumor activity in vitro and in vivo. ${ }^{20} \mathrm{~A}$ favorable safety profile was noted in Phase I and II trials. The most common adverse events included rash and diarrhea, and no cases of interstitial lung disease were reported. ${ }^{21,22}$ Icotinib has a shorter half-life than other EGFR-TKIs such as gefitinib, owing to the different profiles of the P450 metabolism enzymes that metabolize these drugs. ${ }^{23}$ The half-life is $\sim 40$ hours for gefitinib and $\sim 6-8$ hours for icotinib; $;^{21,24}$ hence, gefitinib is taken once a day, whereas icotinib is taken three times a day.

In this study, we evaluated the efficacy and safety of taking $125 \mathrm{mg}$ icotinib three times a day by patients with BMs from lung adenocarcinoma.

\section{Patients and methods}

\section{Patients and treatment}

A total of 28 cases with BMs from lung adenocarcinoma treated with icotinib in Cancer Hospital, Chinese Academy of Medical Sciences, from March 2010 to December 2014 were brought into this study. All patients were diagnosed with BM before taking icotinib. The subjects of this study were treated according to the ethical principles of World Medical Association Declaration of Helsinki, and the study was approved by the Ethics Committee of Chinese Academy of Medical Sciences. All subjects gave their written informed consent.

All the patients took $125 \mathrm{mg}$ icotinib (Conmana ${ }^{\mathrm{TM}}$; Betta Pharmaceutical Co., Ltd., Hangzhou, People's Republic of China) three times a day orally until disease progression or intolerable adverse effects happened.

\section{Outcome assessments}

Complete remission, partial remission (PR), and progression of disease were defined according to the Response Evaluation Criteria in Solid Tumors Version $1.1^{25}$ to evaluate the efficacy of icotinib. Toxic reactions were assessed using Common Terminology Criteria for Adverse Events Version 4.0. ${ }^{26}$

Progression-free survival (PFS) time was defined as the time from the first dose of icotinib to the disease progression first found on imaging. Overall survival time was defined as the time from the first dose of icotinib to the death or the last follow-up of patients.

\section{EGFR gene mutation testing}

EGFR gene mutations were detected in paraffin-embedded tissue sections from the primary tumor. Tumor tissue was scraped from the glass slides under direct visualization or under a dissecting microscope, and EGFR mutations were determined by DNA sequencing as follows: EGFR exons 18-21 were sequenced with a Sanger Sequencing Kit (Thermo Fisher Scientific, Waltham, MA, USA).

\section{Statistical analysis}

SPSS 22.0 (IBM Corporation, Armonk, NY, USA) was used for statistical analysis. Numerical data were expressed as median. Enumeration data were expressed as constituent ratio, and the statistical differences among different groups were assessed by Fisher's exact test. Survival analysis was conducted using the Kaplan-Meier method. $P<0.05$ indicated a significant difference.

\section{Results}

\section{Characteristics of patients with lung adenocarcinoma}

The characteristics of the 28 patients with BMs from lung adenocarcinoma are shown in Table 1 . Seven male and 21 female patients were enrolled with a median age of 59 years (range 37-77 years). There were four patients with a history of smoking.

EGFR gene statuses of 26 patients were detected using the biopsy samples collected by computed tomography-guided lung biopsy or bronchoscopy with biopsy. Twelve patients had EGFR gene mutations (exon 19 or 21) and 14 had wildtype EGFR. Two patients had unknown EGFR gene status because of the absence of the biopsy samples. Among the 16 patients with wild-type/unknown EGFR gene status who had a median age of 57.5 years (range $43-77$ years), there were three men and 13 women, and two of them had a history of smoking.

All patients were diagnosed with BMs from lung adenocarcinoma before taking icotinib, of whom seven patients received cranial radiation before taking icotinib (three patients received whole-brain radiation therapy [WBRT] and four patients received stereotactic radiation therapy) and four patients received WBRT while taking icotinib. Eleven patients were treated for the first time and 17 were retreated patients. Fourteen patients received icotinib as the second-line drug and had received pemetrexed/paclitaxel combined with platinum as the first-line treatment. Three patients took icotinib as the third-line therapy or more than three lines of treatment, and they had been treated with pemetrexed, vinca alkaloids, taxanes, and platinum drugs. 
Table I Characteristics of patients with lung adenocarcinoma $(\mathrm{N}=28)$

\begin{tabular}{|c|c|c|}
\hline Characteristics & $\mathbf{n}$ & $\%$ \\
\hline \multicolumn{3}{|l|}{ Sex } \\
\hline Male & 7 & 25.0 \\
\hline Female & 21 & 75.0 \\
\hline \multicolumn{3}{|l|}{ Smoking history } \\
\hline Yes & 4 & 14.3 \\
\hline No & 24 & 85.7 \\
\hline \multicolumn{3}{|l|}{ ECOG } \\
\hline 0 & 15 & 53.6 \\
\hline I & 9 & 32.1 \\
\hline 2 & 4 & 14.3 \\
\hline \multicolumn{3}{|l|}{ GPA } \\
\hline $0-1.5$ & II & 39.3 \\
\hline $2-3$ & 17 & 60.7 \\
\hline \multicolumn{3}{|l|}{ EGFR status } \\
\hline Mutation & 12 & 42.9 \\
\hline Wild-type & 14 & 50.0 \\
\hline Unknown & 2 & 7.1 \\
\hline \multicolumn{3}{|l|}{ Treatment } \\
\hline Initial treatment & II & 39.3 \\
\hline Retreatment & 17 & 60.7 \\
\hline \multicolumn{3}{|c|}{ Site of first progression } \\
\hline Intracranial & 14 & 50.0 \\
\hline Extracranial & 10 & 35.7 \\
\hline Concurrent & 4 & 14.3 \\
\hline \multicolumn{3}{|l|}{ Number of BMs } \\
\hline $\mathrm{I}-3$ & 19 & 67.9 \\
\hline $4-10$ & 5 & 17.9 \\
\hline$>10$ & 4 & 14.3 \\
\hline \multicolumn{3}{|c|}{ Extracranial metastases } \\
\hline Yes & 25 & 89.3 \\
\hline No & 3 & 10.7 \\
\hline \multicolumn{3}{|c|}{ Cerebral radiation } \\
\hline \multicolumn{3}{|c|}{ Before icotinib treatment } \\
\hline WBRT & 4 & 14.3 \\
\hline SRT & 3 & 10.7 \\
\hline \multicolumn{3}{|c|}{ During icotinib treatment } \\
\hline WBRT & 4 & 14.3 \\
\hline
\end{tabular}

Abbreviations: ECOG, Eastern Cooperative Oncology Group; GPA, Graded Prognostic Assessment; EGFR, epidermal growth factor receptor; BMs, brain metastases; WBRT, whole-brain radiation therapy; SRT, stereotactic radiation therapy.

\section{Patients' survival and progression of disease}

In this study, 20 patients died and eight survived. Disease progressed in 23 cases and five had no disease progression. The median overall survival (mOS) time of patients was 21.2 months, and the median progression-free survival (mPFS) time of patients was 10.9 months. The data of patients' survival are shown in Table 2.

The mOS time of the eleven treatment-naïve patients was 15.2 months and the mPFS time was 14.4 months. The mOS time of the 17 retreated patients was 21.2 months and the mPFS time was 10.5 months. The survival curve is shown in Figure 1.

The mOS time of 12 patients with EGFR gene mutations was 21.2 months and the mPFS time was 12.4 months. The mOS time of the other 16 patients with wild-type/unknown EGFR gene status was 20.4 months and the mPFS time was 10.0 months. The survival curve is shown in Figure 2.

\section{Efficacy of icotinib}

As shown in Table 3, RR, defined as the sum of complete remission rate and PR rate, was $67.8 \%$ in total patients. The disease control rate (DCR) was $96.4 \%$.

For the eleven treatment-naïve patients, RR of icotinib was $81.8 \%$ and DCR was $90.9 \%$. For the retreated patients, RR was $91.7 \%$ and DCR was $100.0 \%$.

For 12 patients with EGFR gene mutations, RR of icotinib was $91.7 \%$ and DCR was $100.0 \%$. For the other 16 patients, RR was $50 \%$ and DCR was $93.8 \%$.

In all, 20 of 28 patients were confirmed dead and eight were alive at the last follow-up. Five patients did not progress and 23 progressed. Sixteen patients had progression of extracranial metastases and 17 had progression of BMs.

\section{Adverse effects}

None of the 28 patients stopped treatment for toxicity and side effects. Only mild adverse events of grade $1 / 2$ were observed during the treatment, including nine cases (32.1\%) of rash, five cases (17.9\%) of diarrhea, and one case of dental ulcer (3.6\%; Table 4).

\section{Discussion}

Icotinib hydrochloride (Conmana ${ }^{\mathrm{TM}}$ ) is the first novel anticancer drug developed by the Chinese pharmaceutical industry and has been approved by the China Food and Drug Administration in June 2011 for the treatment of local advanced or metastatic NSCLC. A nationwide (27 centers), randomized, double-blind, double-modulated, parallel-controlled, Phase III trial with a single agent icotinib in lung cancer patients after failure of chemotherapy demonstrated its validity and safety. ${ }^{27}$

Similar to other EGFR-TKIs gefitinib and erlotinib, icotinib inhibited growth of human tumor cell lines that overexpress EGFR (half maximal inhibitory concentration $1 \mathrm{mmol} / \mathrm{L}$ for A431 cells) and growth of A431 cells (human epithelial carcinomas) in a nude mouse xenograft model. ${ }^{28}$ Moreover, in a tolerance clinical trial implemented by Peking Union Medical College Hospital, icotinib exhibited excellent tolerance among healthy Chinese subjects. ${ }^{22}$ The exact molecular mechanism of icotinib remains unclear. 
Table 2 mOS and mPFS of patients with BMs from lung adenocarcinoma after icotinib treatment

\begin{tabular}{clllll}
\hline & $\begin{array}{l}\text { Total } \\
\mathbf{( N = 2 8 )}\end{array}$ & $\begin{array}{l}\text { Treatment-naïve } \\
\text { patients }(\mathbf{n}=\mathbf{I I})\end{array}$ & $\begin{array}{l}\text { Retreated } \\
\text { patients }(\mathbf{n}=\mathbf{I 7})\end{array}$ & $\begin{array}{l}\text { Patients with EGFR } \\
\text { gene mutations }(\mathbf{n}=\mathbf{1 2})\end{array}$ & $\begin{array}{l}\text { Patients with unknown } \\
\text { EGFR gene status }(\mathbf{n}=\mathbf{1 6})\end{array}$ \\
\hline mOS (months) & 21.1 & 15.2 & 21.2 & 21.2 & 20.4 \\
Range & $2.9-33.6$ & $2.9-31.5$ & $6.2-33.6$ & $6.2-31.5$ & $2.9-33.6$ \\
$95 \% \mathrm{Cl}$ & $16.6-25.6$ & $6.0-24.4$ & $17.2-25.2$ & $10.2-32.2$ & $15.9-24.9$ \\
mPFS (months) & 10.9 & 14.4 & 10.5 & 12.4 & 10.0 \\
Range & $1.1-31.5$ & $1.1-31.5$ & $2.1-23.9$ & $4.8-31.5$ & $1.1-23.9$ \\
$95 \% \mathrm{Cl}$ & $9.7-12.0$ & $6.8-21.9$ & $9.2-11.8$ & $8.1-16.7$ & $6.4-13.6$ \\
\hline
\end{tabular}

Abbreviations: mOS, median overall survival; mPFS, median progression-free survival; BMs, brain metastases; EGFR, epidermal growth factor receptor; Cl, confidence interval.

Our study proved the effectiveness of icotinib in patients with BMs from lung adenocarcinoma. RR and DCR in all 28 patients were higher than those in Zhao et al's study with a RR of $57.3 \%$ and a DCR of $87.8 \% .{ }^{29}$ In Zhao et al's study, icotinib was used as the first-line treatment for preventing BMs from advanced lung adenocarcinoma in patients with EGFR gene mutations. For the patients first treated with icotinib in our study, RR was significantly higher $(81.8 \%$ vs $57.3 \%$ ) and DCR was similar ( $90.9 \%$ vs $87.8 \%)$.

In Porta et al's study, ${ }^{30}$ the median time to progression within the brain for patients harboring EGFR mutations treated with erlotinib was 11.7 months compared to 5.8 months for control patients whose EGFR mutational status had not been assessed $(P<0.05)$ and the mOS time was 12.9 months and 3.1 months $(P<0.001)$, respectively. In this study, patients with EGFR mutations treated with icotinib had a longer mOS time and mPFS time. Previous studies suggested that NSCLC patients with EGFR gene mutations benefited more (higher efficiency and longer survival) from EGFR-TKI treatment than NSCLC patients with wild-type EGFR gene. ${ }^{30,31}$ Park et al ${ }^{32}$ had reported a high response rate of $83 \%$ (23/28) for EGFR TKIs in patients with BM from NSCLC harboring EGFR gene mutations. Also, in our study, the RR and DCR in patients with wild-type/ unknown EGFR gene statuses were high. The reason might be that the EGFR gene statuses were different between the primary tumor and the metastases. ${ }^{33}$ In this study, we did not detect the EGFR gene statuses in BMs due to the limitation of the biopsy methods. As a small molecule TKI, icotinib can cross the BBB, making it possible to achieve the effective therapeutic concentration of drug in BMs to suppress the development of BMs.
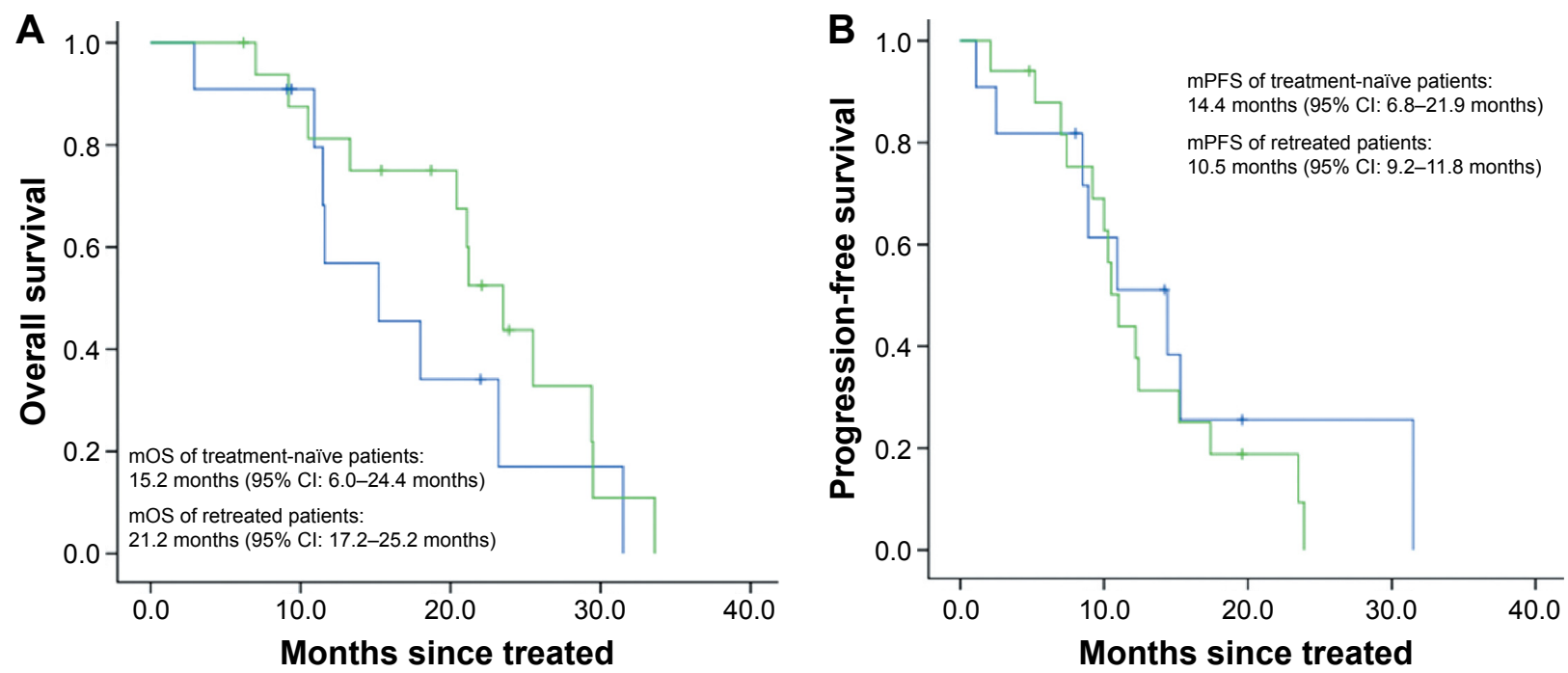

Treatment-naïve patients $\neg$ Retreated patients + Deaths of treatment-naïve patients + Deaths of retreated patients

Figure I Kaplan-Meier curves of patients treated with icotinib for the first time and patients retreated with icotinib.

Notes: (A) Overall survival of patients. (B) Progression-free survival of patients.

Abbreviations: mOS, median overall survival; mPFS, median progression-free survival; $\mathrm{Cl}$, confidence interval. 


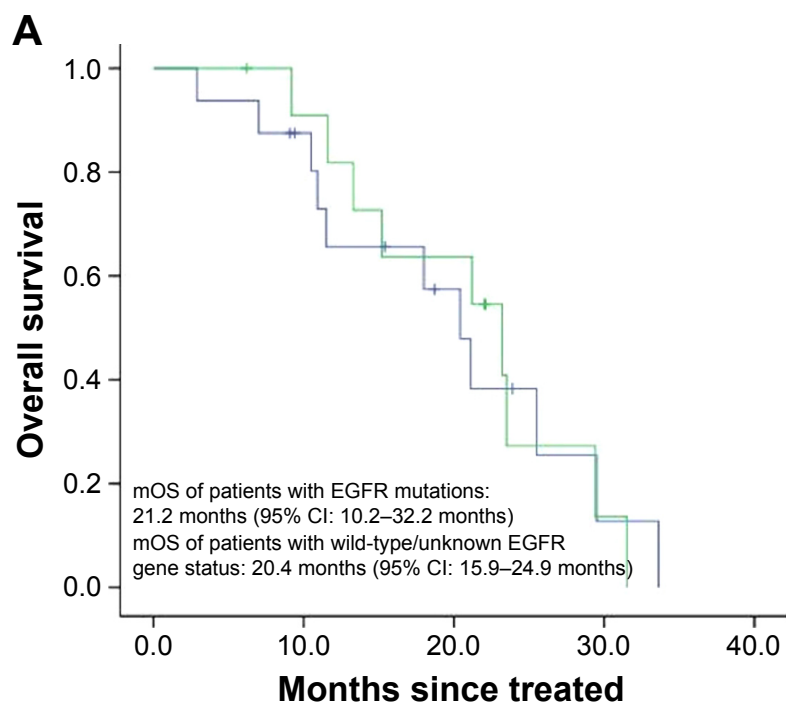

- Patients with EGFR gene mutations
- Patients with unknown EGFR gene status
+ Deaths of patients with EGFR gene mutations
+ Deaths of patients with wild-type/unknown
$\quad$ EGFR gene status
B

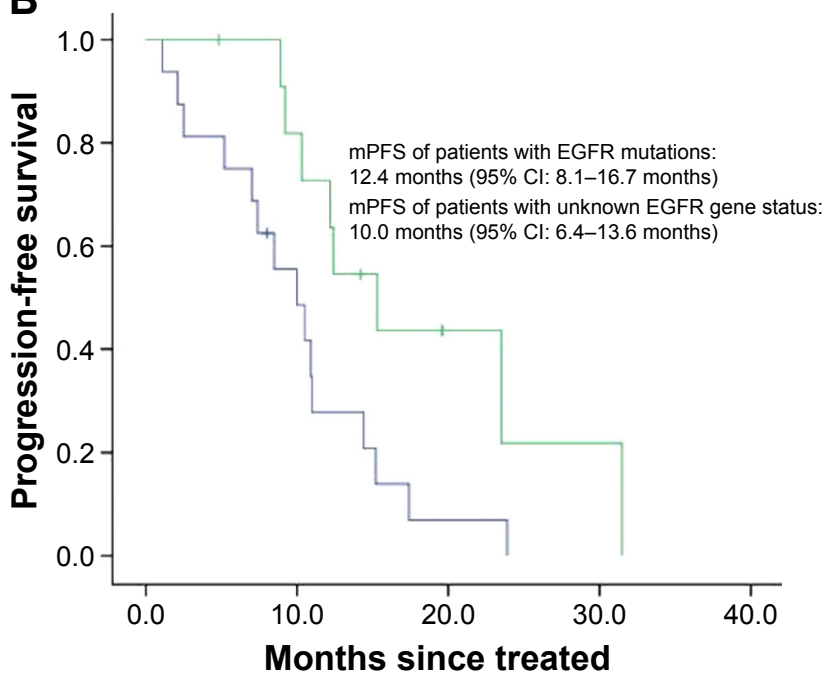

- Patients with EGFR gene mutations
- Patients with unknown EGFR gene status
+ Deaths of patients with EGFR gene mutations
+ Deaths of patients with unknown
EGFR gene status

Figure 2 Kaplan-Meier curves of patients with EGFR gene mutations and patients with wild-type/unknown EGFR gene status.

Notes: (A) Overall survival of patients. (B) Progression-free survival of patients.

Abbreviations: EGFR, epidermal growth factor receptor; mOS, median overall survival; mPFS, median progression-free survival; $\mathrm{Cl}$, confidence interval.

In our study, there were four patients who received cerebral radiation during icotinib treatment. Three of them achieved PR and one patient had stable disease. No intolerable adverse reactions were observed in them. Research in vitro suggested that EGFR-TKIs significantly potentiated the cytotoxic effects of ionizing radiation in human cancer cell lines that expressed functional EGFRs. ${ }^{34}$ The overall response rate was $86 \%$ in a study of erlotinib plus concurrent WBRT for patients with BMs from NSCLC, and the median survival time was 11.8 months. ${ }^{35}$ A Phase II study of icotinib and WBRT in Chinese patients with BMs from NSCLC suggested that icotinib was well tolerated in combination with WBRT and showed efficacy in patients with BMs from NSCLC who harbored EGFR gene mutations. ${ }^{36}$ In contrast, the addition of erlotinib to WBRT combined with stereotactic radiosurgery in the NSCLC patients with one to three BMs did not improve survival and possibly had a deleterious effect. ${ }^{37}$
In our study, only mild adverse effects of grade $1 / 2$ were observed. No liver damage was found in patients. This agreed with other studies. ${ }^{21,38,39}$ This indicated that icotinib was safe for patients with NSCLC.

Unlike other EGFR-TKI drugs, such as erlotinib and gefitinib, which came to the market earlier, there were not enough studies on icotinib. Many questions still need to be answered, for example, should icotinib be taken alone or combined with radiation in patients with BMs from NSCLC.

\section{Conclusion}

Icotinib is effective and safe to treat patients with BMs from lung adenocarcinoma. However, there were some limitations of this study. First, this is a retrospective study. Second, data of the patients were not very comprehensive. Therefore, a prospective study with a large sample size would be needed

Table 3 RR and DCR of icotinib for patients with BMs from lung adenocarcinoma

\begin{tabular}{|c|c|c|c|c|c|}
\hline & $\begin{array}{l}\text { Total } \\
(\mathbf{N}=\mathbf{2 8})\end{array}$ & $\begin{array}{l}\text { Treatment-naïve } \\
\text { patients }(n=I I)\end{array}$ & $\begin{array}{l}\text { Retreated } \\
\text { patients }(n=17)\end{array}$ & $\begin{array}{l}\text { Patients with EGFR } \\
\text { gene mutations }(n=\mid 2)\end{array}$ & $\begin{array}{l}\text { Patients with unknown } \\
\text { EGFR gene status }(n=\mid 6)\end{array}$ \\
\hline RR (\%) & 67.8 & 81.8 & 91.7 & 91.7 & 50.0 \\
\hline DCR (\%) & 96.4 & 90.9 & 100.0 & 100.0 & 93.8 \\
\hline
\end{tabular}

Abbreviations: RR, remission rate; DCR, disease control rate; BMs, brain metastases; EGFR, epidermal growth factor receptor. 
Table 4 Adverse reactions of patients

\begin{tabular}{lll}
\hline Toxicity & $\mathbf{n}$ & $\%$ \\
\hline Fatigue & 20 & 71.4 \\
Dermatology & & \\
$\quad$ Alopecia & 3 & 32.1 \\
Acneiform rash & 9 & 17.9 \\
$\quad$ Ulceration & 1 & 3.6 \\
Gastrointestinal & & \\
Anorexia & 6 & 21.4 \\
Nausea & 15 & 53.7 \\
Vomiting & 6 & 21.4 \\
Diarrhea & 5 & 20.8 \\
Altered taste & 2 & 7.1 \\
Hepatobiliary & & \\
Increased AST/ALT & 1 & 3.6 \\
Increased bilirubin & 3 & 10.7 \\
Neurologic & & 10.7 \\
Headache & 3 & 17.8 \\
Dizziness & 5 &
\end{tabular}

Abbreviations: AST, aspartate aminotransferase; ALT, alanine transaminase.

to adequately evaluate the efficacy and safety of icotinib in patients with BMs from lung adenocarcinoma.

\section{Disclosure}

The authors report no conflicts of interest in this work.

\section{References}

1. Jemal A, Bray F, Center MM, Ferlay J, Ward E, Forman D. Global cancer statistics. CA Cancer J Clin. 2011;61(2):69-90.

2. Herbst RS, Heymach JV, Lippman SM. Lung cancer. $N$ Engl J Med. 2008;359(13):1367-1380.

3. Patchell RA. The management of brain metastases. Cancer Treat Rev. 2003;29(6):533-540.

4. Yawn BP, Wollan PC, Schroeder C, Gazzuola L, Mehta M. Temporal and gender-related trends in brain metastases from lung and breast cancer. Minn Med. 2003;86(12):32-37.

5. D'Antonio C, Passaro A, Gori B, et al. Bone and brain metastasis in lung cancer: recent advances in therapeutic strategies. Ther Adv Med Oncol. 2014;6(3):101-114.

6. Patchell RA, Tibbs PA, Walsh JW, et al. A randomized trial of surgery in the treatment of single metastases to the brain. $N$ Engl J Med. 1990;322(8):494-500.

7. Langer CJ, Mehta MP. Current management of brain metastases, with a focus on systemic options. J Clin Oncol. 2005;23(25): 6207-6219.

8. Cortes J, Rodriguez J, Aramendia JM, et al. Front-line paclitaxel/ cisplatin-based chemotherapy in brain metastases from non-small-cell lung cancer. Oncology. 2003;64(1):28-35.

9. Bailon O, Chouahnia K, Augier A, et al. Upfront association of carboplatin plus pemetrexed in patients with brain metastases of lung adenocarcinoma. Neuro Oncol. 2012;14(4):491-495.

10. Fujita A, Fukuoka S, Takabatake H, Tagaki S, Sekine K. Combination chemotherapy of cisplatin, ifosfamide, and irinotecan with rhG-CSF support in patients with brain metastases from non-small cell lung cancer. Oncology. 2000;59(4):291-295.

11. Ceresoli GL, Cappuzzo F, Gregorc V, Bartolini S, Crino L, Villa E. Gefitinib in patients with brain metastases from non-small-cell lung cancer: a prospective trial. Ann Oncol. 2004;15(7):1042-1047.
12. Hotta K, Kiura K, Ueoka H, et al. Effect of gefitinib ('Iressa', ZD1839) on brain metastases in patients with advanced non-small-cell lung cancer. Lung Cancer. 2004;46(2):255-261.

13. Namba Y, Kijima T, Yokota S, et al. Gefitinib in patients with brain metastases from non-small-cell lung cancer: review of 15 clinical cases. Clin Lung Cancer. 2004;6(2):123-128.

14. Lai CS, Boshoff C, Falzon M, Lee SM. Complete response to erlotinib treatment in brain metastases from recurrent NSCLC. Thorax. 2006;61(1):91.

15. Fekrazad MH, Ravindranathan M, Jones DV Jr. Response of intracranial metastases to erlotinib therapy. J Clin Oncol. 2007;25(31): 5024-5026.

16. Bai H, Han B. The effectiveness of erlotinib against brain metastases in non-small cell lung cancer patients. Am J Clin Oncol. 2013;36(2): $110-115$.

17. Paez JG, Janne PA, Lee JC, et al. EGFR mutations in lung cancer: correlation with clinical response to gefitinib therapy. Science. 2004; 304(5676):1497-1500.

18. Lynch TJ, Bell DW, Sordella R, et al. Activating mutations in the epidermal growth factor receptor underlying responsiveness of non-small-cell lung cancer to gefitinib. N Engl J Med. 2004;350(21):2129-2139.

19. Laurie SA, Goss GD. Role of epidermal growth factor receptor inhibitors in epidermal growth factor receptor wild-type non-small-cell lung cancer. J Clin Oncol. 2013;31(8):1061-1069.

20. Tan F, Shen X, Wang D, et al. Icotinib (BPI-2009H), a novel EGFR tyrosine kinase inhibitor, displays potent efficacy in preclinical studies. Lung Cancer. 2012;76(2):177-182.

21. Zhao Q, Shentu J, Xu N, et al. Phase I study of icotinib hydrochloride (BPI-2009H), an oral EGFR tyrosine kinase inhibitor, in patients with advanced NSCLC and other solid tumors. Lung Cancer. 2011;73(2):195-202.

22. Wang HP, Zhang L, Wang YX, et al. Phase I trial of icotinib, a novel epidermal growth factor receptor tyrosine kinase inhibitor, in Chinese patients with non-small cell lung cancer. Chin Med J (Engl). 2011; 124(13): 1933

23. Liu D, Jiang J, Zhang L, Tan F, Wang Y, Hu P. Metabolite characterization of a novel anti-cancer agent, icotinib, in humans through liquid chromatography/quadrupole time-of-flight tandem mass spectrometry. Rapid Commun Mass Spectrom. 2011;25(15):2131-2140.

24. Ranson M, Hammond LA, Ferry D, et al. ZD1839, a selective oral epidermal growth factor receptor-tyrosine kinase inhibitor, is well tolerated and active in patients with solid, malignant tumors: results of a phase I trial. J Clin Oncol. 2002;20(9):2240-2250.

25. Eisenhauer E, Therasse P, Bogaerts J, et al. New response evaluation criteria in solid tumours: revised RECIST guideline (version 1.1). Eur J Cancer. 2009;45(2):228-247.

26. National Cancer Institute [webpage on the Internet]. Common Terminology Criteria for Adverse Events v4. 0 (CTCAE). Available from: http://evs.nci.nih.gov/ftp1/CTCAE/CTCAE_4.03_2010-06-14_ QuickReference_5x7.pdf. Accessed June 14, 2015.

27. Shi Y, Zhang L, Liu X, et al. Icotinib versus gefitinib in previously treated advanced non-small-cell lung cancer (ICOGEN): a randomised, double-blind phase 3 non-inferiority trial. Lancet Oncol. 2013;14(10): 953-961.

28. Gao Z, Chen W, Zhang X, et al. Icotinib, a potent and specific EGFR tyrosine kinase inhibitor, inhibits growth of squamous cell carcinoma cell line A431 through negatively regulating AKT signaling. Biomed Pharmacother. 2013;67(5):351-356.

29. Zhao X, Zhu G, Chen H, Yang P, Li F, Du N. Efficacy of icotinib versus traditional chemotherapy as first-line treatment for preventing brain metastasis from advanced lung adenocarcinoma in patients with epidermal growth factor receptor-sensitive mutation. J Cancer Res Ther. 2014;10(suppl):C155-C159.

30. Porta R, Sanchez-Torres JM, Paz-Ares L, et al. Brain metastases from lung cancer responding to erlotinib: the importance of EGFR mutation. Eur Respir J. 2011;37(3):624-631. 
31. Eichler AF, Kahle KT, Wang DL, et al. EGFR mutation status and survival after diagnosis of brain metastasis in nonsmall cell lung cancer. Neuro Oncol. 2010;12(11):1193-1199.

32. Park SJ, Kim HT, Lee DH, et al. Efficacy of epidermal growth factor receptor tyrosine kinase inhibitors for brain metastasis in non-small cell lung cancer patients harboring either exon 19 or 21 mutation. Lung Cancer. 2012;77(3):556-560.

33. Kalikaki A, Koutsopoulos A, Trypaki M, et al. Comparison of EGFR and K-RAS gene status between primary tumours and corresponding metastases in NSCLC. Br J Cancer. 2008;99(6):923-929.

34. Bianco C, Tortora G, Bianco R, et al. Enhancement of antitumor activity of ionizing radiation by combined treatment with the selective epidermal growth factor receptor-tyrosine kinase inhibitor ZD1839 (Iressa). Clin Cancer Res. 2002;8(10):3250-3258.

35. Welsh JW, Komaki R, Amini A, et al. Phase II trial of erlotinib plus concurrent whole-brain radiation therapy for patients with brain metastases from non-small-cell lung cancer. J Clin Oncol. 2013;31(7):895-902.
36. Fan Y, Huang Z, Fang L, et al. A phase II study of icotinib and wholebrain radiotherapy in Chinese patients with brain metastases from non-small cell lung cancer. Cancer Chemother Pharmacol. 2015;76(3): 517-523.

37. Sperduto PW, Wang M, Robins HI, et al. A phase 3 trial of whole brain radiation therapy and stereotactic radiosurgery alone versus WBRT and SRS with temozolomide or erlotinib for non-small cell lung cancer and 1 to 3 brain metastases: Radiation Therapy Oncology Group 0320. Int J Radiat Oncol Biol Phys. 2013;85(5):1312-1318.

38. Zheng Y, Fang W, Deng J, Zhao P, Xu N, Zhou J. Sequential treatment of icotinib after first-line pemetrexed in advanced lung adenocarcinoma with unknown EGFR gene status. J Thorac Dis. 2014;6(7):958-964.

39. Hu X, Han B, Gu A, et al. A single-arm, multicenter, safety-monitoring, phase IV study of icotinib in treating advanced non-small cell lung cancer (NSCLC). Lung Cancer. 2014;86(2):207-212.
OncoTargets and Therapy

\section{Publish your work in this journal}

OncoTargets and Therapy is an international, peer-reviewed, open access journal focusing on the pathological basis of all cancers, potential targets for therapy and treatment protocols employed to improve the management of cancer patients. The journal also focuses on the impact of management programs and new therapeutic agents and protocols on

\section{Dovepress}

patient perspectives such as quality of life, adherence and satisfaction. The manuscript management system is completely online and includes a very quick and fair peer-review system, which is all easy to use. Visit http://www.dovepress.com/testimonials.php to read real quotes from published authors. 